\title{
A política sem télos em Jacques Rancière e Michel Foucault
}

\author{
PEDRO CAETANO EBOLI *
}

\begin{abstract}
RESUMO O presente artigo se destina a pensar de que maneira os pensamentos de Michel Foucault e de Jacques Rancière propõem formas políticas sem télos. Ambos os teóricos se distanciam das lógicas que vinculam a política determinados fins bem delineados, se interessando justamente por aquilo que há de incerto e indeterminado nas conseqüencias de sua irrupção. Para estes filósofos a política estaria relacionada, antes de tudo, a acontecimentos, pequenas insurgências que fraturam algo da ordem estabelecida, acarretando na produção de novas subjetividades. Sendo assim, a política aparece como uma ação que se dá primordialmente na ordem dos sujeitos, ou melhor, dos modos de subjetivação. Com este intuito, analisaremos a "atitude crítica", sob as formas de "desassujeitamento no jogo da verdade", que Michel Foucault constrói em seus textos sobre o Aufklärung kantiano. Este conjunto de textos será cotejado por entrevistas e textos para jornal, onde o filósofo deixa entrever algumas de suas concepções políticas. Relacionamos alguns de seus pressupostos às fraturas na partilha do sensível, constitutivas da irrupção política elaborada pelo filósofo Jacques Rancière em O desentendimento. Ao final, associaremos estas elaborações filosóficas a um pensamento que se esforça em "acontecimentalizar" a História, recusando a predominância de uma teleologia que dificilmente abriga a contingência.
\end{abstract}

PALAVRAS-ChaVe Acontecimento; filosofia política; estética e política; modos de subjetivação; crítica

* Doutorando do PPG Design da PUC-Rio, bolsista CAPES 


\section{INTRODUÇÃO}

Nesta exposição concebemos de que maneira os pensamentos de Michel Foucault e de Jacques Rancière propõem formas políticas sem télos. Explicitamos como ambos os teóricos se distanciam das lógicas que vinculam a política a determinados fins bem delineados, se interessando justamente por aquilo que há de incerto nas conseqüencias de sua irrupção. Com este intuito, analisamos inicialmente a "atitude crítica", sob as formas de "desassujeitamento no jogo da verdade", que Michel Foucault constrói em contato com o Kant de “O que são as luzes” '. Em seguida, relacionamos alguns dos pressupostos deste filósofo às fraturas na partilha do sensível, constitutivas da irrupção política elaborada por Jacques Rancière.

Grosso modo, ambos os filósofos compreendem a política como concernente à instauração de uma ruptura com a unidade do sujeito em relação a si mesmo, portanto vinculada àquilo que compreendem por modos de subjetivação. Apesar de produzir implicações muito distintas no interior de cada um deles, esta concepção acaba por pavimentar um solo teórico relativamente comum aos dois autores, em que a política figura como assunto relativo às formas pelas quais somos tornados sujeitos. Assim, ao mesmo tempo em que indicamos algumas similitudes e aproximações, procuramos manter suspensos os pontos em que os dois autores diferem, explicitando suas divergências ao longo do artigo.

Ao final associamos estas elaborações filosóficas a um pensamento que se esforça em acontecimentalizar a História, recusando a predominância de uma teleologia que, em detrimento da necessidade, dificilmente abriga a contingência. Contudo, para se chegar a uma compreensão daquilo que Michel Foucault compreende como "política da verdade" é necessário elucidar alguns dos liames que ele traça entre sujeito e verdade no período final de seu pensamento, que implicam relações estreitas entre ética e política. Estas concepções são constituídas no seio daquilo que o filósofo denomina “diagnóstico" ou “ontologia do presente” ${ }^{2}$.

1 KANT, 1974.

2 Conf. ARTIÈRES, 2004. 


\section{SUJEITO E VERDADE: FOUCAULT E A ONTOLOGIA DO PRESENTE}

A passagem entre as décadas de 1970 e 1980 resultou, para Michel Foucault, em um deslocamento conceitual, que o levaria a afirmar como seu principal interesse não o poder, como se supunha, mas o sujeito ${ }^{3}$. Ou, mais precisamente, as relações entre sujeito e verdade. Este desvio, que de fato não constituiu uma ruptura significativa no pensamento do autor, ficou claro no curso Subjetividade e Verdade ${ }^{4}$, proferido no Collège de France entre 1980 e 1981.

Ali o filósofo passou a direcionar suas atenções para a “experiência dos prazeres na Antiguidade greco-latina" 5 , onde encontrou uma possibilidade conceitual de explorar as relações entre sujeito e verdade através de uma espécie de genealogia da subjetividade ocidental ${ }^{6}$. A este curso se segue A hermenêutica do sujeito ${ }^{7}$ (1981-1982), onde as práticas do cuidado de si o permitem vislumbrar possibilidades de uma participação ativa da constituição dos Antigos enquanto sujeitos, de seus modos de subjetivação. Essas práticas, às quais o conhecimento de si estaria submetido, o levariam justamente ao tema da parresía ${ }^{8}$, que ocupa seus dois cursos subsequentes no Collège de France.

Na primeira aula do curso O governo de si e dos outros, proferida no Collège de France no dia 5 de janeiro de 1983, o filósofo se dedica a escrutinar um texto escrevido por Kant para um jornal alemão, em que ele respondia à pergunta “O que são as luzes?”. Foucault se refere a este texto menor na obra do filósofo alemão como "emblemático, um pouco fetiche" ${ }^{9}$. Ele já havia abordado a Aufklärung kantiana em uma palestra pronunciada cinco anos antes e intitulada O que é a crítica? (Crítica e Aufklärung) ${ }^{10}$. Já seu texto mais famoso, O que são as luzes? ${ }^{11}$, seria publicado um ano depois, em 1984.

3 FOUCAULT, 1995.

4 FOUCAULT, 2016.

5 GROS, 2010, p. 457.

6 GROS, 2016.

7 FOUCAULT, 2010.

8 Michel Foucault caracteriza a parresía como a fala-franca, "o tipo de ato pelo qual o sujeito, dizendo a verdade, se manifesta, e com isso quero dizer: representa a si mesmo e é reconhecido pelos outros como dizendo a verdade" (FOUCAULT, 2011, p. 4).

9 FOUCAULT, 2010a, p. 8.

10 FOUCAULT, 2000.

11 FOUCAULT, 1997. 
A interpretação do filósofo francês, que sem dúvidas parte de uma torção do texto original, permite lançar outras matizes conceituais sobre sua própria trajetória antecedente. Nesta interpretação Foucault explora as relações que ele próprio procurava estabelecer entre ética, política, sujeito e verdade. É curioso, entretanto, que este tributo ao filósofo iluminista tenha ocupado boa parte da primeira aula de um curso dedicado a pensar as práticas da parresía, da fala franca, na antiguidade.

Para compreender as razões deste salto histórico é preciso que tenhamos em mente que, mesmo nos remetendo à Antiguidade Clássica, Michel Foucault se ocupava sempre daquilo que ele denominava diagnóstico ou de uma ontologia do presente.

Em “Não ao sexo rei”, o autor anuncia que a preocupação com o eterno e o imóvel estaria dando lugar a uma filosofia do hoje: “desde o século XIX, a filosofia não parou de se aproximar da questão (...) deste presente que é o que somos”, desconfiando que "talvez não sejamos nada mais e nada além daquilo que acontece atualmente"12. Mas haveria algo de violento, de cortante, nesta filosofia, que "localiza e indica nas inércias e coações do presente os pontos fracos, as brechas, as linhas de força; que sem cessar se desloca"13

Foucault observa uma qualidade semelhante no texto de Kant, compreendendo que na tradição crítica fundada por este filósofo o presente passa a se colocar na ordem de uma diferença: “qual a diferença que ele introduz hoje em relação a ontem?”" trata, portanto, de conceber o presente naquilo em que ele difere de si mesmo, em sua própria imanência. Esta atitude de inquirir o presente sob os termos de uma diferença, que Kant havia levado à cabo respondendo a um jornal da época, se contraporia à ideia do presente enquanto um fluxo linear proveniente do passado ${ }^{15}$.

\section{ÉTICA, POLÍTICA E ATITUdE CRÍTICA}

Assim, este exercício radical que interroga o presente é necessariamente aquele que nos desloca até as fronteiras do pensável, nos limites epistemológicos que estrutu-

\footnotetext{
12 FOUCAULT, 1989, p. 239.

13 Ibid., p. 242.

14 FOUCAULT, 2004, p. 337.

15 “Diagnosticar” in: CASTRO, 2016.
} 
ram nosso pensamento. É na forma destas diferenças, no engendramento de rachaduras entre o visível e o pensável, que Foucault faz inquietar o solo sobre nossos passos. Através de uma integração entre pensamento e uma ação eminentemente violenta o autor faz emergir uma realidade que se apresenta com o frescor do novo, como pura contingência. Essa atitude crítica, constituiria para ele mais que uma teoria, mas um êthos, um ímpeto que não cessa de se recolocar:

É preciso considerar a ontologia crítica de nós mesmos não certamente como uma teoria, uma doutrina, nem mesmo como um corpo permanente de saber que se acumula: é preciso concebê-la como uma atitude, um êthos, uma via filosófica em que a crítica do que somos é simultaneamente análise histórica dos limites que nos são colocados e prova de sua ultrapassagem possível. ${ }^{16}$

Mas se este êthos representaria uma possibilidade incessante de desassujeitamento no jogo da verdade ou, ainda, de indocilidade irrefletida, é precisamente este o método foucaultiano para produzir fraturas nas configurações consensuais de verdade e abrir espaços para novas visibilidades. Assim, a crítica é fundamentalmente heterônoma, só existe em relação a outra coisa que não ela mesma: “ela é instrumento, meio para um devir ou uma verdade que ela não saberá e que ela não será, ela é um olhar sobre um domínio onde quer desempenhar o papel de polícia e onde não é capaz de fazer a lei" ${ }^{17}$.

Todavia, enquanto um filósofo sempre interessado no presente, apresentado como diferença e que acessado por um método genealógico, Michel Foucault parece conjecturar uma possibilidade política para seu próprio tempo nestas análises:

o problema político, ético, social e filosófico de nossos dias não consiste em tentar liberar o indivíduo do Estado nem das instituições do Estado, porém nos liberarmos tanto do Estado quanto do tipo de individualização que a ele se liga. Temos que promover novas formas de subjetividade através da recusa deste tipo de individualidade que nos foi imposto há vários séculos ${ }^{18}$.

Neste sentido, Foucault parece abrir espaço para um modo auspicioso de micropolítica, nunca na forma de um direcionamento ético, mas sob os vultos da irrupção incessante

16 FOUCAULT, 2008, p. 351.

17 FOUCAULT, 2000, p. 2.

18 FOUCAULT, 1995, p. 239. 
de novas subjetividades. Tratam-se de pequenas insurgências aos modos de subjetividade que, como ele mostra, constituem um contínuo entre o indivíduo e o Estado.

Esta experiência ética e política da atitude crítica, entretanto, não pode ser dissociada de sua contingência histórica: para Foucault ela se coloca apenas no período histórico que ele compreende como o "grande processo de governamentalização da sociedade" 19 , "o movimento pelo qual se tratasse na realidade mesma de uma prática social de sujeitar os indivíduos por mecanismos de poder que reclamam de uma verdade" ${ }^{20}$. Este processo teria, historicamente, vinculado modos de produção de subjetividades a formas específicas de produção de verdades, determinado especialmente por aquilo que ele chama de momento cartesiano ${ }^{21}$.

Assim, o teor político da atitude crítica só pode ser compreendido no bojo de uma experiência eminentemente moderna, que tem Kant como um de seus mentores, e que estabelece uma imbricação íntima entre o paradigma da liberdade e o pensamento crítico. E é justamente este dispositivo que coloca em cena um jogo intrincado entre saber, poder e ética, que o filósofo exaure, desde seu âmago. Aqui novamente se insinua a relação de coextensividade que Foucault estabelece entre poder e resistência: “onde há poder há resistência e, no entanto (ou melhor, por isso mesmo) esta nunca se encontra em posição de exterioridade em relação ao poder" ${ }^{22}$. Se o poder não conhece um fora, então é justamente neste tensionamento dos jogos de verdade que a crítica vai operar.

A atitude crítica seria justamente este ethos que permite a saída daquilo que Kant chama de um estado de menoridade. Ela provê autonomia, constitui o "movimento pelo qual o sujeito se dá o direito de interrogar a verdade sobre seus efeitos de poder e o poder sobre seus discursos de verdade”, tendo por função “o desassujeitamento no jogo do

19 FOUCAULT, 2000, p. 6

20 Ibid., p. 5

21 Concebido como ponto de partida do procedimento filosófico, o sujeito formalizado por René Descartes passa a ser colocado como uma substância indubitável que conhece, que é capaz de acesso à verdade. Contudo, aquilo que Michel Foucault compreende por momento cartesiano se refere a um processo social irredutível à figura de Descartes, devendo antes ser compreendida como uma trama historicamente constituída. Nas palavras do filósofo: “quando digo 'momento', não se trata, de modo algum, de situar isso em uma data e localizá-lo, nem de individualizá-lo em torno de uma pessoa e somente uma" (FOUCAULT, 2010, p. 25).

22 FOUCAULT, 2009, p. 105. 
que se poderia chamar (...) a política da verdade" 23 . Assim, a atitude crítica imaginada por Foucault entrelaça fundamentalmente a política a uma ética que não comporta quaisquer formas prescritivas ou télos. A política não é vista por Michel Foucault como um meio para se chegar a determinados fins, mas um exercício incessante que se coloca no âmbito das relações entre sujeito e verdade, nos modos de subjetivação.

\section{JACQUES RANCIÈRE, ESTÉTICA E POLÍTICA}

aqui podemos fazer um paralelo com Jacques Rancière, para quem a política “é assunto de sujeitos, ou melhor, modos de subjetivação" ${ }^{24}$. Para o filósofo a subjetivação é entendida de forma um pouco diferente de Michel Foucault, enquanto um "processo de desidentificação ou de desclassificação" 25 que arranca a "naturalidade de um lugar” ${ }^{26}$. Assim, a subjetivação política

nunca é a mera afirmação de uma identidade; ela é sempre, concomitantemente, a recusa de uma identidade imposta por um outro, fixada pela lógica policial. Com efeito, a polícia quer nomes “exatos”, que assinalam a remissão das pessoas para o seu próprio lugar e para o seu trabalho. Já a política tem que ver com nomes impróprios (...) que articulam uma fala e manifestam um dano ${ }^{27}$.

A subjetivação política produz outros recortes no campo da experiência que insinuam incongruências e paradoxos no sensível partilhado ${ }^{28}$. Para Jacques Rancière a política está intimamente relacionada às experiências sensíveis, e portanto vinculado a uma estética. Mas para que possamos compreender estas formulações é necessário explicitar a antagonismo que o filósofo estabelece entre as figuras da política e da polícia. Grosso modo, a polícia seria composta por um dispositivo cultural que gere as

23 FOUCAULT, 2000, p. 5

24 RANCIÈRE, 1996b, p. 47.

25 RANCIÈRE, 2014, p. 72.

26 RANCIÈRE 1996b, p. 48.

27 RANCIÈRE, 2014, p. 73.

28 Jacques Rancière define como "partilha do sensível à lei geralmente implícita que define as formas do tomar parte, definindo primeiro os modos perceptivos nos quais eles se inscrevem (...). Esta partilha deve ser entendida no duplo sentido da palavra: por um lado, o que separa e exclui, por outro, o que permite participar. Uma partilha do sensível é a forma como se determina no sensível a relação entre um comum partilhado e a repartição de partes exclusivas. Esta repartição que antecipa, pela sua evidência sensível, a repartição das partes e do que não o é, do que se ouve e do que não se ouve" (RANCIÈRE, 2014, p. 146). 
possibilidades de apreensão pelos sentidos e aferição de sentidos, remetendo-os a seus lugares consensuais. Já a política constitui:

o conjunto das atividades que vêm perturbar a ordem da polícia pela inscrição de uma pressuposição que lhe é inteiramente heterogênea. Essa pressuposição é a igualdade de qualquer ser falante com qualquer outro ser falante. Essa igualdade, como vimos, não se inscreve diretamente na ordem social. Manifesta-se apenas pelo dissenso, no sentido mais originário do termo: uma perturbação no sensível, uma modificação singular do que é visível, dizível, contável (...). Antes de ser um conflito de classes ou de partidos, a política é um conflito sobre a configuração do mundo sensível na qual podem aparecer atores e objetos desses conflitos ${ }^{29}$.

Aqui emerge o vínculo de coextensividade entre poder e resistência em Foucault à amarração fundamental entre política e polícia, estabelecida por Jacques Rancière, ainda que este filósofo afirme que "a política não é feita de relações de poder, é feita de relações de mundos" $3^{\circ}$. Em todo caso, com algum esforço poderíamos relacionar as formas do diagnóstico do presente empregadas por Michel Foucault a um caráter eminentemente estético, uma vez que elas estão imbuídas em um "esgarçamento do tecido de nossa rede epistemológica" ${ }^{11}$, nos provendo "novas possibilidades ou novos modos de pensar diferentes" 32 . O próprio filósofo recusava a ideia de desvelar verdades ocultas, mas compunha seus trabalhos de topologias plenamente visíveis.

Em suas palavras ele se ocupava em “tornar visível o que precisamente é visível”, em "fazer aparecer o que está tão próximo, tão imediato, o que está tão intimamente ligado a nós mesmos que, em função disso, não o percebemos" 33 . Pois se a ciência sempre esteve interessada em "conhecer aquilo que não vemos, (...) a tarefa da filosofia atualmente bem poderia ser: quais são as relações de poder às quais estamos presos e nas quais a própria filosofia, pelo menos há 150 anos, está paralisada?"34.

\footnotetext{
29 RANCIÈRE, 1996, p. 374.

30 RANCIÈRE, 1996, p. 54 .

31 BUTLER, 2013, p. 164.

32 Ibid., p. 163.

33 FOUCAULT, 2004, p. 44.

34 Ibid.
} 


\section{POLÍTICA COMO ACONTECIMENTO}

Entretanto, para Jacques Rancière a política não consiste de um exercício ou de uma ética, como em Michel Foucault. Trata-se, em suas palavras, de uma "actividade pontual e provisória"35, motivo pelo qual "a diferença política está sempre à beira do seu desaparecimento" ${ }^{6}$, e não por acaso ele insista no termo “cena” para caracterizá-la. A natureza da política, para o filósofo é antes de tudo disruptiva e instantânea: sua duração é curta e dificilmente seria possível quantificar seus efeitos. Ela ocorre em um instante frágil e efêmero que desestabiliza a ordem do sensível.

Assim, em ambos os teóricos a política prescinde de qualquer expectativa quanto à efetividade em produzir mudanças sociais diretas, muito embora esta possa ser uma decorrência tortuosa de sua irrupção. A política estaria relacionada, antes de tudo, a acontecimentos, pequenas insurgências que fraturam algo da ordem estabelecida, acarretando na produção de novas subjetividades. E neste sentido talvez possamos relacioná-los a um esforço da filosofia contemporânea em acontecimentalizar a história, ou seja, em “fazer surgir a singularidade ali onde se está tentado a fazer referência a uma constante histórica” 37.

Em “É inútil revoltar-se?” de 1979, Michel Foucault responde àqueles que o haviam criticado por ter apoiado a Revolução Iraniana, e deixa claro seu apoio irrestrito às insurreições. Para além de suas conseqüências, neste caso desastrosas, as insurreições seriam dotadas de caráter irredutível, e por este motivo “pertencem à história (...) mas, de certa forma, lhe escapam" ${ }^{38}$. Aqui percebemos que a conceituação foucaultiana de política, assim como a de história, procura se descolar das conseqüencias de uma insurreição. O filósofo prefere se concentrar no acontecimento, naquilo que há de contingente em sua irrupção. Neste sentido, percebemos que tensionar e questionar uma concepção histórica teleológica envolve observar aquilo que há de absolutamente acidental no curso do tempo, mas também uma requalificação do que se compreende por ação política. No mesmo texto o filósofo declara sua visão “antiestratégica”:

35 RANCIÈRE, 2014, p. 153.

36 Ibid, p. 149.

37 CASTRO, 2016, p. 26.

38 FOUCAULT, 2004, p. 77. 
Ser respeitoso quando uma singularidade se insurge, intransigente quando o poder infringe o universal. Escolha simples, obra penosa: pois é preciso ao mesmo tempo espreitar, por baixo da história, o que a rompe e a agita, e vigiar um pouco por trás da política o que deve incondicionalmente limitá-la 39.

Em “What is revolution?” Michel Foucault parece dialogar com este conjunto de questões. A partir de Kant ele anuncia que, “caso fosse capaz de entender a revolução e saber seus desdobramentos, (...) dificilmente um homem sensato a faria” ${ }^{40}$. Entretanto, “o que é importante na Revolução não é a Revolução em si, é o que acontece na cabeça daqueles que não participam dela ou, em qualquer caso, não são os principais atores" (idem), explicitando as mudanças subjetivas ensejadas pelas revoltas.

Assim, ao mesmo tempo que a primazia dos acontecimentos sobre a necessidade faz com que Michel Foucault, seguido de Jacques Rancière, possa vislumbrar a política onde ela antes não se insinuava, esta concepção provê maior mobilidade aos processos históricos. É justamente neste sentido que o filósofo, embora tão preocupado em diagnosticar os perigos do próprio tempo, se declara um otimista absoluto ${ }^{41}$. Pois tudo aquilo que temos por sólido se mostra não passar de uma cena incongruente e intolerável, de um certo desenho efêmero de forças:

existem possibilidades de ação porque é através de muitas ações, reações, etc... através de muitas batalhas, muitos conflitos para responder a um certo número de problemas, que soluções específicas são escolhidas. Eu queria reintegrar muitos fatos óbvios de nossas práticas na historicidade de algumas dessas práticas e, assim, privá-las de seu status de evidência, a fim de devolver-lhes a mobilidade que tinham e que deveriam ter sempre ${ }^{42}$.

Esta visão foucaultiana, profundamente ancorada no lastro da história, não nos lança na noite relativista onde tudo se equivale, uma vez que essa cartografia de poderes, apesar de sua mobilidade e contingência, não cessa de produzir positividades.

39 Ibid., p. 81

40 FOUCAULT, 1997, p. 94, tradução nossa.

41 "Entrevista a Michel Foucault" in: FOUCAULT, 2010b.

42 FOUCAULT, 1997, p. 162, tradução nossa. 


\section{CONSIDERAÇÕES FINAIS}

Deste modo, compreendemos que o pensamento político contemporâneo determinado pelos subsídios teóricos de Michel Foucault, prolongado por Jacques Rancière, situa os modos de subjetivação como objeto de tensionamento central operado pela política. Contudo, estes subsídios teóricos estão ancorados em uma série de pressupostos contra-intuitivos, uma vez que diferem por completo de grande parte da teoria política clássica, segundo a qual as inssureições estariam baseadas primordialmente em relações de fricção entre o governo e a sociedade.

Neste sentido, ao elucidar os elementos microfísicos segundo os quais o poder opera, Michel Foucault deixou um importante legado para a micropolítica. A argúcia do filósofo em diagnosticar os perigos do próprio tempo permitiu todo um novo espectro de ações políticas, em que a teoria acaba vertendo como prática. E não por acaso seu pensamento tenha provisionado importantes subsídios políticos para diversas formas de militância, dentre as quais poderíamos citar o Act-Up ${ }^{43}$ novaiorquino. David Halperin destaca que o "livro de bolso" destes ativistas era o primeiro volume da História da Sexualidade, publicado por Foucault em $1976^{44}$. O autor também explicita que este grupo, fundado em 1987, teria incorporado de forma original, inteligente e criativa as concepções do filósofo sobre sexualidade, saberes e poderes.

O mesmo pode ser deduzido de Jacques Rancière, que “notabilizou-se, nos seus escritos políticos recentes, por ter ultrapassado os limites da academia e influenciado também parte considerável do movimento social" ${ }^{45}$. Suas teorizações imbricam fundamentalmente estética e política, provendo importantes ferramentas conceituais para a análise e para uma miríade de ações ativistas. De forma análoga a Michel Foucault, ele não se deixa circunscrever pelos limites impostos pelos campos do conhecimento, recorrentemente atravessando e tensionando estas bordas estanques. O próprio autor declara: “o que eu sempre tentei fazer foi borrar as fronteiras que separam os gêneros e os níveis do discurso" ${ }^{46}$.

43 Grupo ativista queer, que reivindica políticas públicas de tratamento e prevenção da AIDS desde os anos 1980.

44 Conf. HALPERIN, 1995.

45 HUSSAK, 2017, p. 238.

46 RANCIÈRE, 2011, p. 14, tradução nossa. 
Em todo caso, notamos de que forma as ideias políticas próprias do pensamento de Jacques Rancière e Michel Foucault, apesar de todas as diferenças que possuam, estão fundamentalmente baseadas em uma noção de história que procura tensionar sua matriz hegeliana e teleológica. É curioso que ao dar privilégio aos acontecimentos elas possibilitem uma outra concepção daquilo que venha a ser uma ação política. Aqui, mais uma vez a teoria transborda enquanto ação, complementaridade possível apenas no âmbito de modelos muito específicos de pensamento e de prática filosófica.

\section{BIBLIOGRAFIA}

ARTIÈRES, Philippe. “Dizer a atualidade: o trabalho de diagnóstico em Michel Foucault”. In: GROS, Frédéric (org). Foucault: A Coragem da Verdade. São Paulo: Parábola, 2004. BUTLER, Judith. O que é a crítica? Um ensaio sobre a virtude de Foucault. Cadernos de Ética e Filosofia Política, Vol. 22, n. 1., pp. 159-179, 2013.

CASTRO, Edgardo. Vocabulário de Foucault: um percurso pelos seus temas, conceitos e autores. Belo Horizonte: Autêntica, 2016.

FOUCAULT, Michel. Microfísica do poder. Rio de Janeiro: Graal, 1989.

. “O Sujeito e o poder”. In: DREYFUS, Hubert \& RABINOW, Paul. Mi-

chel Foucault, uma trajetória filosófica: para além do estruturalismo e da hermenêutica. Rio de Janeiro: Forense Universitária, 1995.

. The politics of truth. Nova Iorque: Semiotext(e), 1997.

. "O que é a crítica? (Crítica e Aufklärung)”. In: BIROLI, Flávia; ALVAREZ, Marcos César (orgs.). Michel Foucault: histórias e destinos de um pensamento. Cadernos da Faculdade de Filosofia e Ciências (FFC - UNESP), Marília: Unesp-Marília-Publicações, Vol. 9, n. 1., pp. 169-189, 2000.

. Ditos e Escritos V: Ética, sexualidade, política. Rio de Janeiro: Forense Universitária, 2004.

. Ditos e Escritos II: Arqueologia das ciências e história dos sistemas de pensamento. Rio de Janeiro: Forense Universitária, 2008.

. Vigiar e punir: nascimento da prisão. Petrópolis: Vozes, 2009. 
. A hermenêutica do sujeito: curso dado no Collège de France (19811982). São Paulo: Martins Fontes, 2010.

O governo de si e dos outros: curso no Collège de France (1982-1983).

São Paulo: Martins Fontes, 2010a.

. Ditos e Escritos VI: repensar a política. Rio de Janeiro: Forense Universitária, 2010b.

. A Coragem da Verdade: O Governo de si e dos outros II: Curso no Collège de France (1983-1984). São Paulo: Martins Fontes, 2011.

. Subjetividade e verdade: curso no Collège de France (1980-1981). São Paulo: Martins Fontes, 2016.

GROS, Frédéric. "O cuidado de si em Michel Foucault”. In: RAGO, Margareth; VEIGA-NETO, Alfredo (orgs.) Figuras de Foucault. Belo Horizonte: Autêntica, 2006. . "Situação do curso". In: FOUCAULT, Michel. A hermenêutica do sujeito: curso no Collège de France (1981-1982). São Paulo: Martins Fontes, 2010. "Situação do curso". In: FOUCAULT, Michel. Subjetividade e verdade: curso no Collège de France (1980-1981). São Paulo: Martins Fontes, 2016.

HALPERIN, David. “The Queer Politics of Michel Foucault” In: HALPERIN, David. Saint Foucault: Towards a Gay Hagiography. New York: Oxford University Press, 1995.

HUSSAK VAN VELTHEN RAMOS, Pedro. "Onde há democracia, há também, em princípio, estética”: Jacques Rancière e as novas dinâmicas de organização social. O que nos faz pensar, [S.1.], v. 26, n. 40, p. 237-252, junho de 2017.

KANT, Immanuel. Textos Seletos. Petrópolis: Vozes, 1974.

RANCIÈRE, Jacques. O Desentendimento: política e filosofia. São Paulo: Ed. 34, 1996. . "O dissenso". In: A crise da razão. Adauto Novaes (Org.). São Paulo: Companhia das Letras, $1996 \mathrm{~b}$. . A partilha do sensivel: estética e política. São Paulo: Editora 34, 2009. ."The thinking of dissensus: Politics and Aesthetics". In: BOWMAN, Paul \& STAMP, Richard (orgs). Reading Rancière. Londres: Continuum, 2011. . Nas margens do político. Lisboa: KKYM, 2014. 